\title{
The project Digital Medellín and how to examine the triad of ICT, practice, and learning through change processes with an ethnographic case study approach*
}

\author{
Jan-Ove Christer Olsson** \\ Recibido: 15 noviembre de 2012 - Aprobado: 23 de enero de 2013
}

\begin{abstract}
The main goal of this article is to describe the investigation conducted in the masters' thesis project: Digital Medellin - communities of practice and information and communication technology for organizational development. This is done by giving a description of the background, problem area, the method and theories such as ethnography, a socio-cultural perspective and the concept of communities of practice. Two case studies are presented and discussed. The findings of the research are stated in the form of three principal conclusions.
\end{abstract}

Key words Communication, information and communication technology, culture, practice, change processes, learning.

** Master of Science in Education with a focus on learning, communication and information technology, and Bachelor of Arts in History of Art, both at the University of Gothenburg, Sweden. Lecturer and researcher at the University of Medellín and member of the research group Holográfico at the faculty of communication. E-mail: jolsson@udem.edu.co

* The article is based on the investigation Digital Medellín - communities of practice and ICT for organizational development, which was carried out with an explorative and ethnographic approach in the city of Medellín during the period 2007-2008. The research project was a part of a master's degree at the University of Gothenburg and the faculty of information technology and the department of applied information technology. The thesis applied a focus on learning culture and the learning potential that an organization can have trough taking a strategic view on communities of practice, information- and communication technology (ICT), learning and managing change processes. 


\title{
Proyecto Medellin Digital y cómo examinar la triada de ICT, práctica y aprendizaje a través de los procesos de cambio con un método de caso de estudio etnográfico
}

\begin{abstract}
Resumen
El principal objetivo de este artículo es describir la investigación realizada en el proyecto de tesis de maestria: Medellin Digital-comunidades de práctica e información y tecnología de la comunicación para el desarrollo organizacional. Se ha realizado proporcionando una descripción del background, área problema, método y teorías tales como la etonografía, una perspective socio cultural y el concepto de comunidades de práctica. Dos casos de estudio se presentaron y se discutieron. Los hallazgos de la investigación se muestran con tres conclusions principales.

Palabras clave: Comunicación, información y tecnología de la comunicación, cultura, la práctica, los procesos de cambio, el aprendizaje.
\end{abstract}




\section{Introduction}

This article is based on a masters' project where the main goal was set to examine human behavior and development in the context of some specific roles in an organization that could be described as being in a state of change, and where information and communication technology (ICT) had an important role. The investigation conducted studied some workplace communities on the basis of socio-cultural theory, and the perspective communities of practice (learning practices), and from these viewpoints tried to describe the learning that takes place in them. The main idea was to do a limited exploratory study of some professionals and their workplace practices affected by new infrastructure, new tools and new networks. The study of these unique working communities illustrate how the observed individuals act and appear to be influenced by existing practices and how new networks and new communities of interest are created, and what can be described as a consequence of this fact. The title of the masters' project is: Digital Medellin - Communities of Practice and Information and Communication Technology for Organizational Development'.

\section{Background and problem area}

Our actions and our progress in the professional role are dependent on the social environment, the goals and strategies, and the structure and management of the organization. A well-functioning organization is characterized, in turn, according to Lindmark and Önnevik ${ }^{2}$ (2006, p. 43), "...by a good match between the organizational goals, strategies, the structure, the human resources in relation to the organizational context, and external environment factors". As an employee of an organization I am guided by an employment contract and a job description, and regulated in respect of what I can and cannot do in my professional capacity. In addition to this contract, there are usually a set of rules of conduct and norms of workplace interactions present in some way in the workplace environment. However, this is only part of the control, influence and guidance that exists concerning the staff and their actions and behaviors, there are also unwritten rules and an organizational culture with formal and informal leaders who influence what we are allowed or not allowed to do. It's about a command and control structure that exists in the shape of social groups and power structures in a specific workplace. How this control really works can be difficult to identify precisely because this activity is not regulated in any agreement or in the form of written rules, and much of this type of action takes place in secret, i.e. hidden from those who are not accepted as individuals and members in these social groups. It can also be difficult for a researcher to gain access to all the situations in which these power structures and control mechanisms are manifested, and if access is granted, the participants can through their actions conceal a behavior that may be perceived as controversial

1 Olsson, J-O (2008). Digital Medellin - Communities of Practice and Information and Communication Technology for Organizational Development. Gothenburg: University of Gothenburg and Chalmers University of Technology, Report no 2008:061, ISSN: 1651-4769, Faculty of IT, Department of Applied Information Technology.

2 Lindmark, A. \& Önnevik, T. (2006). Human Resource Management: Organisationens hjärta. Lund: Studentlitteratur. 
and manipulative. The power of the informal governance cannot be underestimated, and therefore the researcher should try to get access to the rooms where these behaviors are reflected in various ways.

If a researcher wants to examine people's actions and professional development he or she cannot simply look at the formal structure of regulation and the official governance in the form of contracts, rules, internal agreements, business plans and meeting decisions. The survey also needs to contain approaches and methods set to possibly identify the informal control and advocacy mechanisms and the possible outcome of such a process, as Raeithel explains in his text about the ethnography of cooperative work:

Thus, a more complete picture of the socially distributed knowledge must also include the exchange relations between different communities of work (Engeström \& Middleton 1998), because the know-how is not only distributed within any one group, it is spread out between groups, too (Raeithel, 1998, p. 3323).

The same chapter also mentions the issue of power relations:

The picture painted of teamwork at the beginning of the last section has also left out intentionally the relations of power, command, and authority, which make it normal for most actors to subject themselves to powerfully upheld demands, and for others to keep those signs publicly 'readable' throughout the working time, be it just by marching around in the workspace, mimetically producing a reminder of their control over the results, or by using a wealth of other semiotic means discovered in industrial sociology, or in recent studies of talk in school classes and clinical groups...(Ibid.).

In working groups and within organizations, there are professional individuals with different roles and powers. There are people who have a supervisory and coordinating role and people who have leadership roles, with the function to organize, manage and develop a business with the support of communities of practice; that's to say those who occurs in public, which is not always the case: ..."if it occurs publicly at all, and not completely outside the focal community of practice" (Ibid.). This study believes it is important that we are aware that there exists an ongoing discussion in the workplace and inside the practices of the organization, even when invited researchers are absent and when the formal leader isn't participating. This daily agenda is probably not documented. This investigation had the objective to study some professional workplace communities or communities of practice $e^{4}$ and to produce a description of reality that more clearly could identify and point to the existing relationships that affect and explain an organization and its professionals' actions and development. Through interviews and surveys it can be difficult to obtain a basis which confirms and describes these structures and its form and nature, especially when it may be sensitive and difficult for the individuals to comment on that. Therefore, the study also used other forms of data production, like observation and participation in some professional practices, meanwhile trying to find a factual basis which could also

3 Raeithel, A. (1998). On the ethnography of cooperative work. Chapter 14 in Engeström, Y. \& Middleton, D., eds. (1998). Cognition and Communication at work. Cambridge, UK: Cambridge University Press.

4 Refers to the term as depicted by: Wenger, E. (1998). Communities of Practice - Learning, Meaning, and Identity. Cambridge, MA: Cambridge University Press. 
illustrate the informal discussions and processes in a professional and learning experience, a professional learning practice, or a community of practice.

In this masters' project, specific cases were studied which illustrate different actions and beliefs that educators/teachers, librarians, library managers and school leaders show in their professional roles in the context of an organizational change in which information and communication technology (ICT) and formal and informal learning practices plays an important role. The study set out to examine the following questions: What motivates employees to develop their professional roles? What specific areas of their professional practice do they want to develop and how do they believe they can do it? What impact do they believe the development of their own professional practice can have on the rest of the organization? The significance ICT has in this, and how the ICT changes which has occurred within the organization and how it has influenced the development of the organization was other aspects to be investigated. The study also tried to look for signs that could identify the importance that the various learning practices, or communities of practice, played in this context.

Using an ethnographic method, this investigation hoped to study, to illustrate and describe how some school leaders, teachers, librarians and library managers in some parts of an organization, or an educational and cultural institution in transition, have acted, argued and communicated when they were affected by a change in ICT in the form of new infrastructure, new ideas and working methods. By observing and participating in the employees professional practice the study was seeking insight and data that could explain and identify their educational learning practice, from a community of practice perspective, and how is was affected, changed and evolved.

\section{The reasons and objectives for doing this investigation}

An investigation of learning practices, or communities of practice, implicates a focus on learning as an essentially collective process, rather than seeing it as a predominantly individual and internal one. This focus also lead the study to undertake an investigation of the concept of practice and examine its possible importance and how fragile a practice can be. Additional aspects that the investigation wanted to study included: learning taking place in a specific practice and its relationship to the organizational learning, the effects of ICT and change processes. This type of investigation can begin with various methods and theories. This masters project decided to plan and organize two case studies that could be observed to learn more about the character of a learning practice. With the help of these case studies the investigation wanted to contribute with more data in this research area. ICT is so ubiquitous in our society today that it affects most people in some way. The research case selection aimed to develop and study a comprehensive development project in another country in this case, Colombia. The project Digital Medellin started under the administration of Mayor Sergio Fajardo Valderrama (elected for the period 2004-2007) and was continued by his successor Alonso Salazar Jaramillo (elected mayor for the term

Anagramas Volumen 11, № 22 pp. 113-130 ISSN 1692-2522 Enero-Junio de 2013. 212 p. Medellín, Colombia 
2008-2011). Since each case that was studied in this work had its own special conditions, it created a new image and a new description of how learning practices can occur, can be created, and can function.

The investigated and described cases consisted of cultural and educational learning practices in a city which had been relatively non-digitized because of lack of public resources and lack of political will to change this fact. The study describes what happens when the situation changes and the political decisions arise in a new situation, where one goes from a largely non-digitized environment to become digitized in a significantly greater extent than before. What happens to the individuals and their behavior, their learning and development, their professional practice and their social and cultural environment, within an organization affected by change in systems of information and communication technology? That question seemed very interesting to study. The principal goal was to investigate what happens in a learning practice of some professionals and how that perspective could illustrate the process which affects humans as part of their professional role and learning experience in a transitioning organization where ICT plays an important role. By implementing an exploratory study with its unique conditions the investigation had a real opportunity to find new data that further could describe and explain this.

\section{Method and theories}

To a large extent, the study assumed the theories and analytical perspectives that Wenger, and also Lave $\mathcal{E}$ Wenger, presents in their work on Situated Learning, legitimate peripheral participation ${ }^{5}$, and Communities of practice $^{6}$. Furthermore, the influence of my point of view and my way of approaching the socio-cultural networks and the learning practices described in the study. The socio-cultural, or cultural-historical, perspective rooted in the Russian psychologist L. S. Vygotsky's theories, and subsequent researchers' interpretations as well as further work in the theory area, also have a strong influence in describing, understanding and analyzing the investigated case studies. The masters' project also chose to implement a study with an ethnographic approach applied to research concepts and analysis. For the investigation this means an influence in terms of a participatory perspective, with the risks and benefits that may be a result of this. The study deliberately chose to take an exploratory and problematic unveiling approach as the basis for the review and analysis that it presents. As Wenger points out in his book, Communities of Practice, the investigation doesn't believe that a single theory or perspective can explain everything and therefore does not replace other theories about learning. The study recognizes that there exists other theories and beliefs, but it chose not to make a more detailed description of them in the thesis work, instead this thesis preferred to mention various works in the reference list, and among them there exists several examples of alternative theoretical perspectives.

5 Lave, J. E Wenger, E. (1991). Situated learning - Legimate peripheral participation. Cambridge, MA: Cambridge University Press.

6 Wenger, E. (1998). Communities of Practice - Learning, Meaning, and Identity. Cambridge, MA: Cambridge University Press. 
By using a case study approach the investigation takes the position that an ethnographic method is the most appropriate way to approach the problem area. The deep description of people, practices, and learning in social networks and the socially and culturally influenced relations that the case study strives for, is also subject to a fundamentally socio-cultural perspective. A description of such a perspective can be done by applying an ethnographic method: "The application of ethnographic methods to work research, then, begins by our viewing each work group or organization as a culturally alien community whose world-model and practices we must reconstruct from the utterances and situated actions of the working persons" (Raeithel, 1998, p. 3207).

Should we study learning from a sociocultural perspective, one need to pay attention to three different but interacting, phenomena according to the Swedish scientist Roger Säljö ${ }^{8}$ :

1) The development and use of intellectual (or psychological/linguistic tools, 2) Development and use of physical tools, 3) Communication and the ways in which people have developed forms of cooperation in various collective activities the authors translation from Swedish] (Säljö, 2000, p. 23).

The study also recognizes the fact that the researcher moved from a Swedish environment and that socio-cultural context, to a Colombian environment and another socio-cultural context. This movement certainly affects the way a researcher understands, describes and interprets the culture of the people that he met on location in Medellín, Colombia. The thesis report was written in Swedish, and for a Swedish audience, which meant a necessary linguistic translation of interviews, conversations and survey responses. The description of the project Digital Medellin and the individuals and professional practices that were observed is thus done with a specific cultural perspective, and that perspective is also affected by the socio-cultural environment that the researcher was influenced by on-site in Colombia for five months. Finally, it should be said that we cannot avoid being affected and we cannot avoid the learning that takes place from our experiences.

\section{Ethnography and case study approach}

The study used an ethnographic case study method and the main reason for this was that the investigator should be able to focus on the culture that manifested itself in a few professional learning practices, or communities of practice. The perspective applied in the study is also a socio-cultural approach and the researcher used the theory, or perspective, of communities of practice as a screen, an approach to describe, explain and understand what he as an investigator observed on the study subjects, groups and their organizations.

"Ethnography takes the position that human behavior and the ways in which people construct and make meaning of their worlds and their lives are highly variable and locally

7 Raeithel, A. (1998). On the ethnography of cooperative work. Chapter 14 in Engeström, Y. \& Middleton, D., eds. (1998). Cognition and Communication at work. Cambridge, UK: Cambridge University Press.

8 Säljö, R. (2000). Lärande i praktiken: Ett sociokulturellt perspektiv. Stockholm: Bokförlaget Prisma. 
specific" (LeComte $\mathcal{E}$ Schensul, 1999, p. $1^{9}$ ). The tools for an ethnographer consists of the tools that can be used to detect, and the most prominent of these tools is the researcher, the ethnographer, and his or her ability to see, hear and perceive the environment being studied. It is through systematic field studies that the ethnographic researcher learns and gathers data in the form of observations, interviews and other available ways of recording and producing data. Ethnographic research method is therefore no objective description of the reality or something that is performed in a laboratory where the researcher strives to control the experiments so that they can be repeated several times under exactly the same conditions. An ethnographic researcher cannot control what happens in the field study, the researcher is invited as a guest to learn what happens in the social context in which the study takes place.

Scientific ethnographic research is conducted in field settings where the researcher enters as an 'invited guest' to learn what is going on. Thus, the ethnographic field situation is unlike clinic- or laboratory-based experimental research, where most aspects of the environment are controlled and where researchers can use the same instruments and can expect to get the same results if the study is repeated (LeComte $\&$ Schensul, 1999, s. 2).

What is ethnography then? Lecomte $\mathcal{E}$ Schensul indicates that it means to write about human beings (1999, p. 21) and more specifically it means to write about a culture of a group of people.

All ethnographers begin - and end - their work with a focus on these patterns and traits that, lumped together, constitute a people's culture. The result of such a focus is the document we call ethnography.

Culture is not an individual trait of a single person, if you cannot recognize these behaviors in a group of people we cannot say that there is a culture, says the authors (Ibid.). Culture can be regarded as a mental phenomenon, which consists of what people know, think, understand, feel or mean by what they do. Culture can be said to be what we need to know to be able to function in social contexts in which we are members. Culture can also be considered based on what people actually do and not based from what they say they do (which is not always consistent with what they actually do). Both the behavioral and the cognitive, emotional, aspects of the concept of culture takes place in an economic and political context characterized by some special social events: "Thus, culture also includes the social arrangements and institutions within which people interact, or that are designed to meet their instrumental or emotional needs" (Lecomte E Schensul 1999, p. 23).

This does not mean that all individuals in a culture share the same beliefs or behave the same way. As individuals we are unique and there is also a variation among us in the form of differences such as backgrounds, gender, age, race, education level, place of residence and income, and in ethnographic studies it's important to see these types of differences and therefore do not attempt to describe or portray the individuals in the study as too

9 LeCompte, M. D. E Schensul, J. J. (1999). Designing E Conducting Ethnographic Research. Lanham, MD: AltaMira Press. 
stereotypical. It is also important to consider that the individual in a culture belongs to a group in which social structures are maintained as they are continually reproduced and therefore it's very interesting to study the everyday behavior in these structures.

Ethnography is a science and it gives the researcher the opportunity and tools necessary to enter new field studies and examine the newly identified social issues or behaviors without being hampered by the previous use of tools or assumptions about relationships (Ibid., p. 38). Ethnography as a method can be used in several areas: e.g. to better understand a situation or problem, to document and explain better what is happening in a study area, to complement other research approaches, to supplement quantifiable data and instruments, and ethnography can also be used to identify emerging trends and new solutions to social problems (Ibid., p. 39). The population of selected case studies can be chosen in different ways and with different justification. The ethnographic researcher describes why a group of people should be investigated and the criteria used when selecting cases to be investigated. The selection criteria concern: the logistics criteria, defining criteria and conceptual criteria. The researcher needs to consider all of these criteria (Ibid., p. 111). This masters' thesis study used what Lecomte \& Schensul call: Unique Case selection and Comparable Cases selection (Ibid., p. 114).

\section{A socio-cultural paradigm/perspective}

We can relate to learning in different ways. We can understand it as an organized activity in a school environment, we can see it as a relationship between the apprentice and masters, or we can see learning as an aspect of all human activity. "In a more fundamental sense learning is about what individuals and collectives take away from social situations and use in the future" (Säljö, 2000, p. 13). Säljö also describes learning as something characteristic of the human species and that this activity is done individually as well as collectively and he states that the learning process has evolved and developed over time, with new technology and social development (Ibid.). According to several researchers, the social and cultural environment we grow up in and are brought up with affects and characterize us as individuals in a very large extent. One of the forerunners in the research area that can be called socio-historical, cultural historical or socio-cultural is the Russian psychologist and educational theorist: Lev Semenovich Vygotsky. According to Vygotsky humans are affected by a historic experience and a social dimension that makes the individual able to "acquire and incorporate the huge repository of other experiences" (Bråten, 1998, p. 14 ${ }^{10}$ ). Vygotsky emphasized the importance of the social aspect and the impact on individuals, according to Bråten (Ibid.), and he quotes Vygotsky in English (the author read the Swedish version and the translation into English comes from that text): "The social dimension of consciousness is primary in time and in fact. The individual dimension of consciousness is derivative and secondary". This constitutes the foundation for Vygotskyss socio-historical theory of higher psychological processes, continues Bråten, and describes Vygotskyss theory a little more in detail [the author's translation]:

10 Bråten, I., ed. (1998). Vygotskij och pedagogiken. Lund: Studentlitteratur. 
- According to Vygotsky, the mans higher psychological processes have a social, historical and a socio-historical quality. The natural or nature-given is lower, elementary processes. Unlike these, the higher psychological processes are to be considered artificial. To higher psychological processes Vygotsky firstly counted for the cultural and cognitive tools such as language, writing, storytelling and drawing, and secondly for the other traditional cognitive processes like logical memory, selective attention and concept formation (Ibid., 1998, p. 14).

Bråten develops the description of Vygotskyss theory and speak about the qualitative differences that Vygotsky believed existed in the higher psychological processes and lower and more natural forms of memory and attention. The higher psychological processes are socially determined, which means that they are a result of social activity and thus also social in nature (Ibid.). He then enters the concept of mediation, where he also cites Vygotsky [the author's translation of the Swedish text here):

- Social activity mediates higher psychological processes. Children function later independent in the way that they previously did in collaboration with others. First appears the psychological processes in their higher forms in the children's social lives, supported by the interactions they participate in. Later on the children transfer this social way of thinking to their own inner psychological world: "Every function in the child's cultural development appear twice: first on the social level, and later, on the individual level, first, between people (interpsychological), and then inside the child (intrapsychological)" (Bråten cites Vygotsky, 1978, p. 57).

Of the cultural expressions and culture carriers, which Vygotsky is talking about, the human language takes a special status, according to Bråten (1998, p. 15). Through the social interaction that the individual participates in the symbols and characters are woven into his psychological processes and lifted to a higher plane. This social interaction is based on a historical basis and is expressed in a socio-cultural context.

Säljö discusses the circumstances in which we learn: for what purpose, how much, and in what way we learn, and which cultural practices we use and how they depend on «...in which cultural circumstances we live in» (Säljö, 2000, p. 14). We can learn by memorizing texts or stories, we can learn by going to an encyclopedia or a book to find the information we're looking for, we can call a person or interview someone who knows what we want to know, we can look for information on the internet or we can attend a conference or participate in an conference call with the help of information and communication technology. We use different types of tools to learn and develop as individuals and as a collective group. It is therefore not only a question of our individual intelligence or our individual ability to perceive and understand things that are important for our ability to learn and develop. «We are biological beings, but live simultaneously in a socio-cultural reality with access to different kinds of aids and tools that take us far beyond the limits of our own biology» (p. 17). Learning from a socio-cultural basis thus becomes a question of «...how we acquire the resources to think and carry out practical projects that are part of our culture and our environment» (Ibid., p. 21). 


\section{Communities of Practice}

The concept of communities of practice (CoP) are taken from the book with the same name and, adding: Learning, Meaning, and Identity (Wenger, 1998). Wenger anchors the term in turn to the collaboration with his research colleague Jean Lave that resulted in the publication of the work: Situated Learning - Legitimate peripheral participation (Lave $\mathcal{E}$ Wenger, 1991). Wenger uses this concept to describe the social theory of learning which he presents and develops in his book. This social theory of learning, has a number of starting points for the following argument, including the description that learning, and the nature of learning, is based on four premises:

1) We are social beings. Far from being trivially true, this fact is a central aspect of learning.

2) Knowledge is a matter of competence with respect to valued enterprises - such as singing in tune, discovering scientific facts, fixing machines, writing poetry, being convivial, growing up as a boy or a girl, and so forth.

3) Knowing is a matter of participating in the pursuit of such enterprises, that is, of active engagement in the world.

4) Meaning - our ability to experience the world and our engagement with it as meaningful - is ultimately what learning is to produce (Wenger, 1998, p. $4^{11}$ ).

The primary of these premises and this theory is about a social participation by various groups (not only in the small and local context but also in a wider social context) in which we construct our identity in relation to the social groups we belong to. The groups we belong to affect what we do, who we are, and how we perceive what we do, says Wenger (Ibid., p. 4-5). Learning takes place on an individual level with different circumstances, but it also happens to a large extent in social settings and in groups that develop their special learning practices. Most of us probably know this, and can agree with that description of how it works, but how can we describe it in a systematic way, asks Wenger, and there we have the foundation of the social theory of learning as he presents (p. 8). If we can understand these relationships better we can act differently in relation to the learning that inevitably arises. Maybe we can design learning differently in our institutions, our business or within the organization to which we belong (p. 11).

The perspective of focusing on the social structure and participation within it, is also a perspective that focuses on the individual as a member of a socio-cultural context and in the world (Lave \& Wenger, 1991, p. 52). Lave and Wenger also speak about the distinction between "a learning curriculum" and "a teaching curriculum", where the former is about the possibilities to, in an improvised manner, develop new practice, and the latter is about a perspective which assumes the assumption that you can teach something to someone ("newcomers") and thus organize and control how this learning should be organized (Ibid., p. 97).

11 Wenger, E. (1998). Communities of Practice - Learning, Meaning, and Identity. Cambridge, MA: Cambridge University Press. 
The development of an identity is something central to the newcomers career in a CoP and it is fundamental to the concept of legitimate peripheral participation, says Lave and Wenger (1991, p. 115). This theme is developed further by Wenger (1998, p. 215) when he describes "Learning and identity in practice". He believes that learning changes who we are and what we can do, and in that way, it is about our identity. There isn't a question of a simple accumulation of knowledge, skills and information, but in the process of becoming one, or avoiding becoming another, you create and develop your identity. This creation of identity includes a learning with both a process and a place where both knowledge and context change. To support learning is then to support the process where learning is produced, to offer a place where new types of knowledge can be developed and form such identity. This is an approach to learning, and the study aimed to investigate if it could trace such a strategy in the design of the learning practices (COP) that the study set out to investigate and observe in the project Digital Medellin. What makes the information into knowledge is the way that it can be integrated with an identity based on participation. Knowing in practice is then to create a special identity so that information can achieve accordance with the participation in practice (Ibid., 1998, p. 220).

In making information more widely available, what the technological advances of so called information society really do is create wider, more complex, and more diversified economies of meaning and communities. With respect to the potential for learning communities, issues of identification and negotiability are then heightened, not transcended (Ibid., p. 221).

In the case of using CoP as a perspective and a tool for analysis, one wonders how the model is constructed and what kind of analysis can be done with it. Wenger claimed that the concept of CoP is an analysis of medium level (1998, p. 124). This analysis tool does not represent a narrowly defined task or interaction, nor does it relate to the broader defined aggregation that is historically or socially abstract.

Wenger defines (p. 125) what characterizes and indicates that a community of practice has been established and in that description indicates that the three dimensions; mutual engagement, a joint enterprise, a shared repertoire, appear on a significant scale. What we have is thus a notion of practice which is a social structure and that reflects a shared learning. This refers to both a level of analysis and the construction of experience. Since we do not normally think of a social group in these terms, most of us do not perceive ourselves and our lives in this way, but in this way it becomes a question of an analytical categorization (p. 126). This level of analysis is not a mysterious categorization level that refers to abstract forms of social clusters, rather it refers to structures that we can understand and which we are familiar with from our world, and therefore it is not just something analytical. In the survey of the project Digital Medellin, it becomes clear that there is not a question of abstract types of social clusters, but it is about concrete social structures and groups that form different types of learning practices. There is also a connection to ethnography as a method, which just like CoP is about the study of individuals in a social culture and the relationships and identity that occurs in such a socio-cultural context. 
It is important to understand what distinguishes the organization and a community of practice to not confuse their roles. Wenger mentions three dimensions identifying a community of practice: CoP negotiates its own meaning, CoP arises, evolves and dissolves in relation to their own learning, and CoP creates its own borders. The designed form of the organization can be contrasted with the constellations of practices that exist within the organization and thus constitute important parts of the organization (p. 241). Both of these together make up what the organization is. The relationship between organizational structure and CoP (a learning practice) is not a relationship of accordance says Wenger (p. 245) but it is about a negotiated approach/orientation. Practice and organization can never be united, because they are different unities, and the negotiation between them is constantly going on, precisely because they are different and complement each other as resources for the structure. "The point of design for learning is to make organizations ready for the emergent by serving the inventiveness of practice and the potential for innovation inherent in its emergent structure" (Ibid.).

Instead of focusing on education, the organization may choose to concentrate on learning and an organizational structure for learning. If you think in that way you lift up the learning from a secondary function to a key organizational issue. The purpose of doing this is not primarily to shape and deliver courses but rather to develop the learning potential of the organization (Ibid., p. 250).

\section{The investigation}

The design of the investigation is based on an ethnographic case study method in which non-probability sampling is used to qualitatively illustrate some cases. The researcher used qualitative instruments to produce data and to obtain a depth description as a basis for interpretation and analysis. These instruments consists of: policy documents, directives, laws, agreements, blogs, web pages, portals, forums, surveys, interviews, observations and participation in professional activities and learning practices. In order to triangulate the data the investigation use several types of data output in the same case study area. To control them the researcher asks several people the same thing and compares this data with the information the investigation gets from various official documents.

The ethnographic strategy aims at producing an optimal written record and a vivid description of such action-relevant meaningful spaces, leaving the criticism and correction of the explanations specific to a particular work area either totally to the experts in the field or handling over its own results to a subsequent phase of theoretical or design-related analysis (Raeithel, 1998, p.334).

By making several studies within the same investigation area and then examining them critically and comparing them with each other, the investigation strives to get a better foundation that provides a deep description of different conditions and angles of approach. The study chose to examine two cases within an overall project with the same ethnographic research method and by comparison between the two cases the investigation presents the results in the form of a deep description, the processing and analysis of data

Anagramas Volumen 11, № 22 pp. 113-130 ISSN 1692-2522 Enero-Junio de 2013. 212 p. Medellín, Colombia 
and the thesis argue that the conclusions can be made from these specific cases. The investigation doesn't take a position on whether more general conclusions can be made from this material as it was not the purpose of this exploratory study.

The population and eligibility criteria for the cases studied are made by what in ethnographic method is described as: criterion-based selection, where the researcher makes a selection based on the characteristics that are studied in the survey. The selection can be done in different ways and in this case, the selection processes that are called unique case selection and comparable case selection (Lecomte \& Schensul, 1999, pp. 113-114). Unique case selection is about a selection that is unique, unusual and difficult to accurately copy. Comparable case selection is when the researcher chooses cases that are similar and contain the characteristics that will be studied. My sample consists of two cases, the organization Red de Bibliotecas and the school Héctor Abad Gómez within the context of the educational and cultural project, Digital Medellín. The sample of schools was made by selecting the first completed and operational of 10 so called colegios de calidad (quality schools) on the grounds that the school had reached the highest in the process of installing and embracing the new technology involved in the project Digital Medellin and that the investigation in that school was able to get access to a group of ICT/computer science teachers who participated in a learning practice in a process of change influenced by ICT. In the case of Red de Bibliotecas librarians where chosen as the professional practice of analysis and within this library network the study chose the libraries CREM Granizal and San Javier La Loma because these libraries had already worked with various types of ICT projects and thus had come a long way in the change process to assimilate the new information and communication technology tools that come with the project, Digital Medellin. The ability to make an additional survey on the entire population of librarians, within the network Red de Bibliotecas, was also an advantage that the researcher considered in the selection process. The project Digital Medellin was chosen because it was (at the time for the study) a timely and unique project in education and culture in which they were consciously using the concept of learning practices (CoP) to influence and develop different types of organizations and professionals through both a traditional (face2face) and technology-based manner (ICT/ virtual/digital) for the socio-cultural networking.

The whole investigation was constructed and conducted in eight steps: preparations, the survey phase, the case study description, processing and analysis, conclusions, review, publishing, and feedback. The study phase was conducted through the time span of September 2007 until February 2008. The empirical research material was analyzed and processed in several stages and from different angles. The thesis has an interpretation of the ethnography and the professional practices that the case studies are depicting through the perspective and with the screen that the perspective of communities of practice and the theories of learning from a socio-cultural perspective have been able to give the study. Since the ethnographic approach does not claim to be generalizable to a larger population than the cases investigated, the empirical material, the review, analysis and conclusions of these, will be presented to be further assessed and analyzed through the deep description that the study presents and, based on the theoretical 
approach that are specifically stated in this article in a compressed and therefore not complete form.

The units of analysis are the organizations, groups of professionals and their professional practice, which the study has chosen to focus on in the investigated population. In the case study Institución Educativa Héctor Abad Gómez it is the schools ICT or computer science teachers that the investigation primarily chose to follow and study and secondary observing and exploring other teachers and the school leaders. In the case study about the library network Red de Bibliotecas the investigation followed and studied the visible network activity of the librarians on the internet portal (reddebibliotecas.org.co) and the formal and informal practices where the researcher was able to participate. The librarians in the network Red Bibliotecas was also offered to participate in a survey. The study concentrated the participant observation on two library leaders and their activities and behavior; the library leaders in the libraries CREM Granizal and San Javier La Loma.

Processing and analysis of an ethnographic data set can be organized and structured with the aim to perform in three phases and abstraction levels: subject level, pattern level and structural level (Lecomte E Schensul, 1999, pp. 150 151). The investigation was influenced by those abstraction levels and used them as a guide in the processing and analysis and for the reasoning and interpretations of the case studies. Important parts of the extensive ethnographic data were presented in the section processing and analysis, and this also constituted the data for the conclusions. The analysis and findings related to the problem and the survey questions presented and the theoretical approach that was outlined. The process of processing and analysis have also consisted of a comparison of the data produced in order to be able to contrast them against each other and to investigate whether there are similarities and differences. The comparisons have been made on the basis of the concepts: subject level, pattern level and structural level. The scientific starting points and the theoretical reasoning and the models that the investigation presented about communities of practice and a socio-cultural paradigm/perspective has been the starting point for the identification of relevant subject matters, patterns and structures.

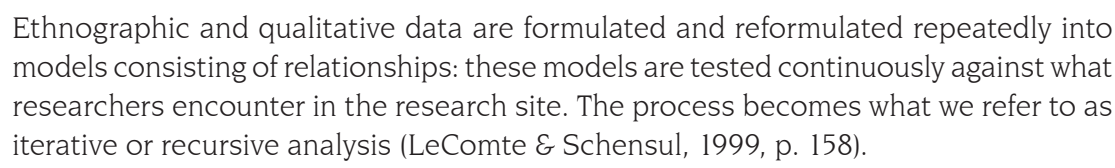

This investigation was not intended to confirm a hypothesis, but the primary goal was to in an exploratory manner search for possible answers to the study questions by using the deep descriptions produced by the ethnographic case studies. The aim was not to find a precise definition or categorization of what constitutes a learning practice or a CoP, and when you can say that there is evidence for that such a practice exist. The viewpoint and perspective of communities of practice was used primarily to detect, describe, understand and interpret the learning and the processes of change that are taking place in such learning situations. Therefore, the empirical study in itself was the focus of this research report. 


\section{Conclusions}

The conclusions made by the masters' thesis study are based in large part from an ethnographic perspective, but it also takes a management perspective, when performing the analysis about how the staff and activities can be developed. The study has been able to detect three things: (i) It is important that there is a strategic approach to the concept of communities of practice and ICT and the role they can play in processes of change (ii) Formal and informal practices are complementary (iii) The organization is unique in its history, personnel and culture, and negotiate the conditions until it finds the optimal balance in relation to practices (P), information and communication technology (ICT), learning and change processes $(\mathrm{L}+\mathrm{CP}$ ). The point with this is to make them receptive and open to new and unexpected ideas and results.

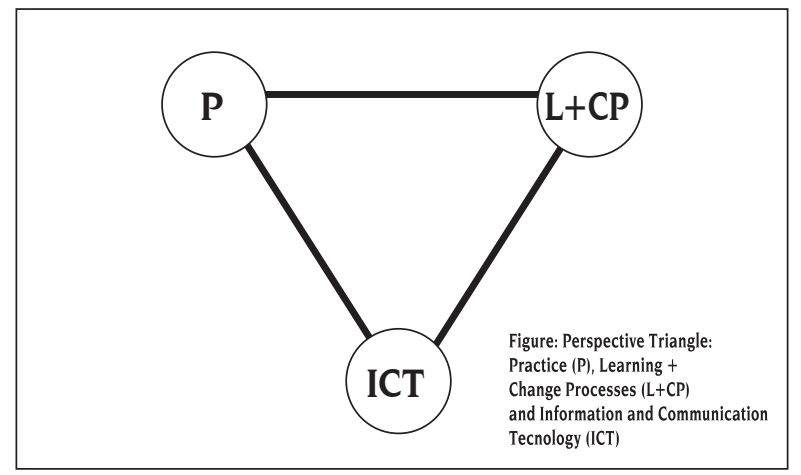

Figure: Perspective Triangle

(i) It is important to have a strategic approach to the communities of practice and ICT and the role they can play in processes of change to give legitimacy to the practices and to send the signal that they have an important role in the organization, for the personnel and the business development process.

In the research material, there are signs that there exists a conscious approach to communities of practice, and the role and strategic importance these may have in a process of change and in the development of the organization. The investigation identified this at the highest level of management within the city department of Education and Culture as well as among the leaders of the EPM foundation and in other organizations in various ways involved in the project, Digital Medellin. It is the researcher's understanding that the leaders of the EPM foundation were connected to the research society and had personal contacts with investigators that can be identified and related to the knowledge about the theories of communities of practice, change processes and ICT. This had a significant impact on what the researcher observed of the nature of the project Digital Medellin. The study can interpret it as a cultural expression that shows itself in many ways in the ethnography from the way that this is mediated to the researcher. The study illustrates that the project has begun a comprehensive process of change that is influenced by a massive introduction of 
new infrastructure, new technologies and tools. The researcher perceives this change as strategic, initiated and controlled from the overall planning and management level in the city of Medellín. The study interprets the ethnographic material so that there exists different types of formal learning practices at many levels and they are supported by a reference to the idea that they can generate a knowledge and learning in them that affect individuals, organizations and society. When several leaders from the top control level express their support for the idea of investing in different types of learning practices the investigation interpret it as a cultural expression. The study has discovered written goal statements of what the leaders want to accomplish with the project Digital Medellin, but the researcher also found that there was a dialogue and discussion, in practice, about the objectives and how to achieve them. Possibly there may be an idea that the process of change can better be accepted by applying such an approach. When analyzing the ethnographic material at a slightly lower leadership level, the study detected that school leaders and library leaders have a different approach and a different daily practice to depart from. They participate actively in various learning practices; different communities of practice, but the investigation do not believe that these leaders have an equal clear approach to how they place and value the different practices in relation to the organizational structure and how these structures are negotiating their direction/orientation. At this leadership level, it isn't so clear that there is a strategic understanding of how the organization can relate to the practices and the learning that goes on there. It is perhaps asking too much of the leaders at that level that they shall have such a viewpoint based on their role, as they are in the midst of an extensive change where they focus more on practical, operational issues than on the strategic. Based on the research data, the interview and observational data, the researcher concluded that leadership at school management and library management levels need to better understand why it might be a good idea to have a strategic approach to the practices, so that they can place and evaluate these in relation to the organizational structure they manage and to gain insight into how they can make this a central organization concern at the organizational level. This is important if it will be possible to realize the idea of using learning practices, (or CoP), as instruments to develop the organization's learning potential and build architecture for learning in this way.

\section{(ii) Formal networks and informal practices are complementary.}

When it comes to learning practices from the viewpoint of the investigated ICT/computer science teachers and librarians perspective, it refers to the processes of change and learning which can take place both in formal and informal ones. This study has come to the conclusion that both types play an important role with the conversation, the experience, the identity, the stimulus and the learning that are produced within them, and how that learning affects the organization in different ways. The professional and learning practices that this investigation has been able to examine, shows that the human resource of the organization are motivated and want to learn and develop in their professional field and therefore engage themselves in various way in several learning practices, both formal and informal. This learning takes place both with a clear support from the organization and management, and this occurs even when the support is weak or where the support isn't

Anagramas Volumen 11, № 22 pp. 113-130 ISSN 1692-2522 Enero-Junio de 2013. 212 p. Medellín, Colombia 
clearly articulated. This shows that informal practices occur when they are needed and that it is better if there is both acceptance and space for this to happen. The study therefore concludes that the formal and informal practices are complementary.

(iii) The organization is unique in its history, personnel, culture and negotiates it's way to the optimal balance in relation to practice (P), information and communication technology (ICT), learning and change processes $(L+C P)$. The point with this has to do with making an organization receptive and open to new and unexpected ideas and results.

The organization and practice complement each other as structural resources. Both are important in their way, the organization stands for its resources and the practices ensure that what they want to accomplish is done. If the organization is focusing on the relationship practices $(\mathrm{P})$, its use of $\mathrm{ICT}$, the learning $(\mathrm{L}+\mathrm{CP})$ and the change processes that exists and lifts it to a central organizational level, the organization also focuses on the organization's potential for learning and on their learning culture. The way to do this is to utilize the knowledge and ideas that emerge in practice. Furthermore, the organization must make itself receptive to the emergence of new and unexpected results that can come out of the interaction between individuals in practices and their behavior within the organization. The synergy and complex completeness that can be created out of this can be a competitive advantage for the organization. There is no perfect socio-cultural formula that a leader or a management team can use to form the social processes in the organization and find the optimal balance in the relationship (P), (ICT), ( $\mathrm{L}+\mathrm{CP})$, because each organization is unique in its people and their mix of knowledge and involvement in a variety of practices and the culture and history the organization has produced. The point is to take an active approach to this and to be open and ready to support the new and unexpected that may arise in the practices. 